\title{
Understanding Flipped Learners' Perceptions, Perceived Usefulness, Registration Intention, and Learning Engagement
}

\author{
Min Young Doo \\ Department of Education, College of Education, Kangwon National University, South Korea \\ ORCID: 0000-0003-3565-2159
}

Received: 2 Jul 2021

Accepted: 26 Sep 2021

\begin{abstract}
This study investigated flipped learners' perceptions, perceived usefulness, intention to register for flipped learning classes, and learning engagement using cluster analysis with a sample of 306 undergraduate students in flipped classes. The students were classified into five clusters based on their level of social influence and cognitive instrumental processes using the technology acceptance model 2. There were significant differences among the five clusters in perceived usefulness, intention to register for flipped learning classes, and learning engagement. The perception of and preference for flipped learning also varied by cluster. The flipped learning feature that most participants commented on was online pre-learning sessions. The advantages of flipped learning that have to do with online pre-learning sessions include facilitating understanding of lectures, providing review opportunities for learning, flexible learning time, and individualized learning. These advantages indicate that providing students with instructionally sound pre-learning sessions leads to successful flipped learning. The research findings also suggest that flipped class instructors and school administrators utilize cluster analysis with meaningful variables to provide students with effective and tailored learning support.
\end{abstract}

Keywords: flipped learning, perceptions of flipped learning, perceived usefulness, learning engagement, registration intention, cluster analysis

\section{INTRODUCTION}

Flipped learning has become an increasingly popular option in higher education (Johnson et al., 2015; Lee \& Choi, 2019; Steen-Utheim \& Foldnes, 2018). The rapid growth of flipped learning is due to its strengths as an instructional approach, such as improved learning engagement, cost-efficiency of implementing learnercentered approaches to a large number of students, and increased learning outcomes (Al-Samarraie et al., 2019; Bergmann \& Sams, 2012; Fulton, 2012). He et al. (2016) described three components of flipped learning: "Flipped classrooms should feature (1) mandatory pre-class learning of new material followed by (2) in-depth explanation, practice, and productive use of knowledge in class through active learning techniques, where (3) class attendance is mandatory" (p. 61). Goodwin and Miller (2013), and O'Flaherty and Phillips (2015) also explained that flipped learning is the best practice of blended learning, which has recently become popular in higher education. It has recently become even more popular as institutions have shifted to online formats due to COVID-19 pandemic restrictions.

Flipped learning requires students to complete pre-learning sessions prior to class and then participate in engaging learner-centered activities in class. Lee and Choi (2019) emphasized the significance of pre-learning sessions for effective flipped learning courses. They found that the influence of pre-learning sessions on the success of learning outcomes was approximately twice as large as outcomes with in-class learning. On the 
negative side, however, He et al. (2016) pointed out that non-compliance with watching or reading materials for pre-learning sessions is a hindrance for flipped learning. This barrier indicates that the roles and responsibilities of students in flipped learning classes are considerably different than in traditional lecturebased classes. The requirements and expectations of students in flipped learning classes are also quite different from how students have been used to learning (Ng, 2018). Koh (2019) found that students perceived that flipped classes require more time to learn the pre-learning materials and reported having a heavier workload. For these reasons, students' perceptions of flipped learning and their motivations for choosing flipped learning classes may be different from the perspectives of instructors or school administrators.

As more students have recently enrolled in flipped learning classes in higher education, the perceptions and needs of students for flipped learning have become more diverse (Forsey et al., 2013; Hao, 2016). Based on their scoping review of flipped learning, O'Flaherty and Phillips (2015) reported that students' perceptions of flipped learning were largely positive; however, they also identified negative perspectives of flipped learning. Hao (2016) examined undergraduate students' perceptions of flipped learning and concluded that flipped learning cannot be applied to "all students, all contexts, and all disciplines." While substantial research on flipped learning has examined the effectiveness and efficiency of flipped learning, including Forsey et al. (2013), Hao (2016), He et al. (2016), O'Flaherty and Phillips (2015), Nouri (2016), and Wang and Zhu (2019), few studies have explored students' perceptions of and intention to register for flipped learning classes with the segmentation of learners. The segmentation of flipped learners is expected to enable instructors or school administrators to apply effective instructional strategies and provide appropriate learning support in flipped learning. Given that there is a wide range of students' perceptions of and needs for flipped learning, this study classified flipped learners into meaningful groups using cluster analysis by applying the extension of the technology acceptance model (TAM2) (Venkatesh \& Davis, 2000).

TAM2 is an extension of Davis' (1989) technology acceptance model developed by adding two external processes (i.e., social influence and cognitive instrumental processes) to increase its explanatory power. The purpose of this study is to understand flipped learners' perceptions, perceived use, intention to register for flipped learning classes, and learning engagement using cluster analysis. We posed two research questions to guide the study:

1. Do perceived usefulness, intention to register for flipped learning classes, and learning engagement of flipped learners differ among groups with different levels of social influence and cognitive instrumental processes?

2. What are students' perceptions of and preferences for flipped learning? What do students like the most and the least about flipped learning?

\section{LITERATURE REVIEW}

\section{Students' Perceptions of Flipped Learning}

Flipped learning is defined as "a pedagogical approach in which direct instruction moves from the group learning space to the individual learning space, and the resulting group space is transformed into a dynamic, interactive learning environment where the educator guides students as they apply concepts and engage creatively in the subject matters" (Flip Learning, 2014). Flipped learning has been touted as an effective instructional approach from the perspectives of instructors, school administrators, and education researchers (Hwang et al., 2019; Steen-Utheim \& Foldnes, 2018). McDonald and Smith (2013), and O'Flaherty and Phillips (2015) listed the advantages of flipped learning including "encouraging students to become selfdirected learners," "flexibility in learning," and "promoting ownership of learning." Koh (2019) conducted an extensive literature review and summarized the effectiveness of flipped learning in higher education, including (1) personalization, (2) higher-order thinking, (3) collaboration, and (4) self-direction. Steen-Utheim and Foldnes (2018) conducted a research investigating the perception of flipped learning from students' perspectives. They examined the affective dimension of learning engagement of flipped learners using qualitative data with 12 freshmen at a Norwegian business school who were enrolled in both a flipped class 
and a traditional lecture-based class. The results of the data analysis yielded the following seven themes about flipped learning: (1) commitment to peers, (2) learning with peers, (3) being recognized [as individuals], (4) reduced anxiety [or obtaining emotional safety], (5) using videos to learn new content, (6) [different] instructor relationship, and (7) physical learning environment [different from traditional lecture-based classes]. Based on these research findings, Steen-Utheim and Foldnes (2018) emphasized the importance of students' perceptions of flipped learning and affective learning engagement for successful learning outcomes.

Given that flipped learning is a learner-centered instructional approach and requires students to play a more active role in learning, students' perceptions of and preferences for flipped learning is important for successful learning outcomes. To examine students' perceptions of flipped learning, O'Flaherty and Phillips (2015) conducted an extensive review of 28 relevant studies on flipped learning in higher education and found that students' perceptions of flipped learning were largely positive; however, some students had negative perspectives of flipped learning. In other words, flipped learning is not applicable or satisfactory for all students. Hao (2016) also analyzed students' perceptions and readiness level for flipped learning with 84 undergraduate students in Taiwan. Around $60 \%$ of the participants were positive about flipped learning in general. However, only $39.3 \%$ reported that flipped learning met their learning needs and only $44 \%$ said that they would take flipped courses in the future. What students liked about flipped learning included, "recognition of learning needs," "more interaction in classes," and "more effective use of class time." However, students disliked the "requirement for self-discipline," "the requirement of prior knowledge and academic motivation," and that they had "less learner control."

Forsey et al. (2013) also surveyed 74 students in a sociology class using flipped learning in Australia and found that only slightly more than half $(53 \%)$ of the students indicated that flipped learning suited their learning needs. What aspects the participants valued in flipped learning included "flexibility," "the richness of the learning content," and "productivity in learning." The students were also concerned that online pre-learning might substantially replace instructor-led lectures. Wang and Zhu (2019) also examined 73 first-year students' perceptions of flipped learning in a chemistry course using MOOC-based flipped learning materials in China. Although there were significant learning gains for the flipped learners, student evaluations of the overall learning experience were slightly lower than their learning performance. Wang and Zhu found that most students liked the student-student interaction and active learning results in class; however, the prelearning materials (i.e., using existing MOOCs) did not satisfy students' needs. This finding indicates that there should be a good fit between the pre-learning materials and class activities.

Nouri (2016) also compared the effectiveness of flipped learning between high achievers and low achievers in a university in Sweden. The participants of their study had positive perceptions of flipped learning as an instructional approach in terms of the use of video, flexibility, and mobility, all of which support learning with meaningful learning activities. Although no significant differences in the attitudes toward flipped learning were found between high achievers and low achievers, the study found that the low achievers appreciated the use of video more as pre-online learning materials than the higher achievers. In addition, the perceived learning gains of low achievers were higher than the high achievers. Nouri explained that low achievers may benefit more from flipped learning due to the individualization (e.g., more opportunities to learn at their own pace) and repetition (e.g., ability to pause and rewind the pre-learning online materials).

He et al. (2016) investigated the effects of flipped learning on learning outcomes and students' perceptions of flipped learning with 676 freshmen using a treatment and comparison group design. They found that flipped learning slightly increased students' final exam performance, but not motivation. He et al. (2016) reported that the participants in the treatment group reported mixed feelings about flipped learning. Exemplary positive comments about flipped learning included, "learning at one's own time and pace, better preparation for class, and more problem solving and teacher-student interaction" (p. 70). These studies on students' perceptions of flipped learning reveal a wide range of student perceptions and intention to register for flipped learning classes. To implement flipped learning more effectively, it is necessary to understand learners' perceptions at a deeper level (e.g., using segmentation or clusters) to help instructors and administrators apply customized instructional strategies that address the preferences of each learner cluster. 


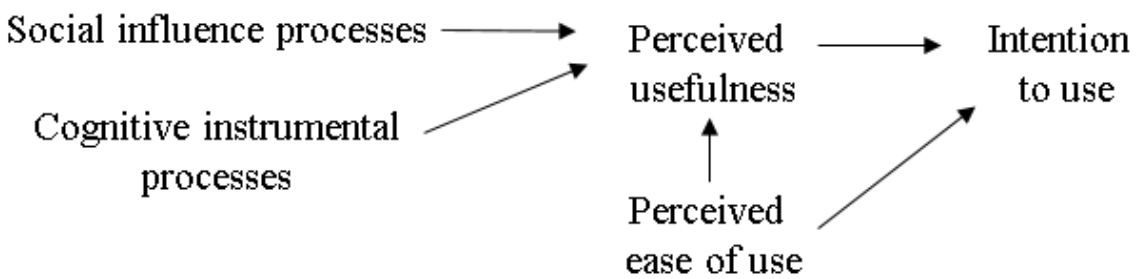

Figure 1. Technology acceptance model 2

Note: Restructured extension of the technology acceptance model (Venkatesh \& Davis, 2000, p. 188)

\section{Technology Acceptance Model 2}

The technology acceptance model (TAM) (1989) has been used to explain adoption of innovation or new technologies in various realms including in education (Abdullah \& Ward, 2016; Agudo-Peregrina et al., 2014; Chen Hsieh et al., 2017; Park et al., 2012). TAM explains that two critical elements, perceived usefulness and perceived ease of use, largely determine individuals' technology adoption. Perceived usefulness, which refers to "the degree to which a person believes that using a particular system would enhance his or her job performance" (Davis, 1989, p. 320), has been reported to be a robust predictor of technology adoption. In particular, perceived usefulness accounts for approximately $60 \%$ of intention to use (Venkatesh \& Davis, 2000). Given the importance of perceived usefulness, Venkatesh and Davis (2000) added two external processes to perceived usefulness in their extended TAM model (TAM2): social influence processes (e.g., subjective norms and personal image) and cognitive instrumental processes (e.g., job relevance, output quality, and result demonstrability) to improve its explanatory power (see Figure 1).

Social influence processes indicate the influences of social forces (e.g., subjective norms and one's personal image) on individuals' perceived usefulness and intention to use new systems. Subjective norm refers to individuals' perceptions of the expectations or pressure from important referents (Agudo-Peregrina et al., 2014; Venkatesh \& Davis, 2000). Personal image refers to individuals' desire to portray a good image by following subjective norms to enhance membership as an inner circle member (Davis, 1989).

In contrast, cognitive instrumental processes refer to individuals' general cognitive processes, including job relevance, output quality, and result demonstrability, impacting their rational decisions about whether to adopt an innovation to maximize their utility (Venkatesh \& Davis, 2000). Job relevance refers to "a function of the importance within one's job of the set of tasks the system is capable of supporting" (Venkatesh \& Davis 2000, p. 191). Output quality indicates how effective it (flipped learning) is to obtain desirable learning outcomes or achieve expected results (Mitchell \& Beach, 1976). Since social influence and cognitive instrumental processes influence perceived usefulness and intention to use, this study classified flipped learners using these two external processes and then compared the clusters in students' perceptions, perceived usefulness, intention to register for flipped learning classes, and learning engagement.

\section{METHODS}

\section{Context and Participants}

The participants of this study were 306 undergraduates who were enrolled in flipped learning classes in the 2019 fall semester at a university in Korea. The survey was administered electronically using a Google survey. The survey link was passed on to students by nine professors teaching flipped learning courses. The survey was conducted two weeks prior to the end of the semester. The participants voluntarily completed the survey with no extra course credit (survey response rate: 68.45\%) and there was no disadvantage for those who did not participate in the survey.

More female students ( $N=167,54.6 \%)$ participated in this study than male students $(N=139,45.4 \%)$. The distribution of the class year of the participants ranged from freshmen $(N=73,23.9 \%)$, sophomores $(N=101$, $33.0 \%$ ), juniors ( $N=91,29.7 \%)$, to seniors $(N=41,13.4 \%)$. Since the survey was conducted across majors, the 
Table 1. Research instruments

\begin{tabular}{lcc}
\hline Variables & Number of items & Cronbach's alpha \\
\hline Subjective norms & 2 & .80 \\
Personal image & 3 & .80 \\
Relevance for learning & 2 & .87 \\
Quality of learning outcomes & 2 & .89 \\
Perceived usefulness & 4 & .96 \\
Registration intention & 2 & .96 \\
Learning engagement & 10 & .89 \\
\hline
\end{tabular}

Note: Adapted and modified from Venkatesh and Davis (2000), and Schreiner and Louis (2011)

majors of participants varied widely, including energy resources (16.0\%), nano-material science (15.7\%), English language and literature (10.8\%), education (10.1\%), chemistry (10.1\%), and others.

\section{Research Process and Measurement Instruments}

This study included two parts: (1) classifying the participants into meaningful clusters, and (2) making comparisons among the clusters for perceived usefulness, learning engagement, intention to register for flipped classes, and perceptions of flipped learning.

The survey consisted of 32 questions, including demographic information ( 7 items) and questions measuring seven primary variables: subjective norms ( 2 items), personal image ( 3 items), relevance for learning ( 2 items), the quality of learning outcomes ( 2 items), perceived usefulness ( 4 items), and intention to use ( 2 items), and learning engagement (10 items). To measure the seven variables, we adapted and modified the TAM2 measurement (Venkatesh \& Davis, 2000) except two items of voluntariness. Since taking flipped classes was not mandatory, voluntariness was not applicable to this study. Learning engagement was measured with 10 items of Schreiner and Louis' (2011) scale.

The survey questions were translated into Korean with reference to each original scale and then modified to make them more appropriate for a flipped learning context at a university in Korea (see Table 1). The survey was reviewed by two experts in the educational technology field. The participants were asked to answer each question on a 5-point Likert scale from 1 "strongly disagree" to 5 "strongly agree." The participants were also asked an open-ended question about their perceptions of flipped classes. Table 1 describes the measurement scales of this study, including the number of items and the Cronbach's alphas for the latent variables. The reliability coefficients for the latent variables were satisfactory given that Cronbach's alpha for each latent variable was higher than .80 .

\section{Data Analysis}

Prior to conducting the cluster analysis, we checked the normality assumption and the common method bias. Descriptive data including the means, standard deviations of the measurement variables, and correlations are shown in Table 2. The skewness and kurtosis of all variables ranged from -1 to 1 ; thus, the normal distribution assumption was acceptable (George \& Mallery, 2010).

Since the data of the current study were collected using one method (i.e., a survey), we performed Harman's single-factor test to detect common method variance. The test results indicated that there was no common method variance because the total variance for a single factor was $39.25 \%$, which is less than $50 \%$ (Podsakoff et al., 2003).

To classify the participants into meaningful clusters, we conducted a cluster analysis using social influence (SI) and cognitive instrumental $(\mathrm{Cl})$ processes. Cluster analysis refers to "a data reduction technique to reduce a large number of observations into a smaller number of groups" (Pastor, 2010, p. 41). Since SI and Cl processes are external factors of perceived usefulness and intention to use in TAM, we selected these variables for the cluster analysis. Since the number of clusters was unknown, we performed a two-step cluster analysis including (1) hierarchical cluster analysis and (2) (a non-hierarchical) K-means cluster analysis. 
Table 2. Descriptive data

\begin{tabular}{lccccccc}
\hline Variables & 1 & 2 & 3 & 4 & 5 & 6 & 7 \\
\hline Subjective norms & 1 & $.74^{* *}$ & $.75^{* *}$ & $.67^{* *}$ & $.67^{* *}$ & $.67^{* *}$ & $.70^{* *}$ \\
Personal image & & 1 & $.74^{* *}$ & $.62^{* *}$ & $.70^{* *}$ & $.72^{* *}$ & $.70^{* *}$ \\
Relevance for learning & & & 1 & $.78^{* *}$ & $.74^{* *}$ & $.74^{* *}$ & $.71^{* *}$ \\
Output quality & & & & 1 & $.65^{* *}$ & $.66^{* *}$ & $.63^{* *}$ \\
Perceived usefulness & & & & & 1 & $.87^{* *}$ & $.72^{* *}$ \\
Registration intention & & & & & & $.74^{* *}$ \\
Learning engagement & & & & & & & 1 \\
Mean & 3.31 & 3.16 & 3.60 & 3.69 & 3.88 & 3.85 & 3.36 \\
SD & .99 & .90 & 1.01 & 1.02 & .98 & 1.09 & .81 \\
Skewness & -.20 & .09 & -.43 & -.48 & -.72 & -.83 & .00 \\
Kurtosis & -.23 & -.05 & -.15 & -.27 & .08 & .09 & .25 \\
\hline
\end{tabular}

Note: ${ }^{* *} p<.001,{ }^{*} p<.05$

Table 3. Final cluster centers for five clusters

\begin{tabular}{lccccc}
\hline Cluster centers & Cluster 1 & Cluster 2 & Cluster 3 & Cluster 4 & Cluster 5 \\
\hline Subjective norms & 4.76 & 3.42 & 1.93 & 3.26 & 2.21 \\
Personal image & 4.36 & 3.42 & 2.13 & 2.97 & 2.20 \\
Relevance for learning & 4.82 & 4.24 & 1.81 & 3.17 & 3.38 \\
Quality of learning results & 4.90 & 4.36 & 1.74 & 3.19 & 3.41 \\
\hline
\end{tabular}

The purpose of hierarchical cluster analysis is to identity the number of clusters and cluster centers and the results are prerequisites for conducting K-means analysis (Aldenderfer \& Balshfield, 1984). The hierarchical cluster analysis was performed using the Ward method based on squared Euclidean distance. Dendrogram, a visual representation showing the hierarchical relationships among cases, showed that five clusters were the most reasonable for the current data. Data analysis was performed using the statistical software SPSS (version 24.0).

\section{RESULTS}

\section{K-means Cluster Analysis}

We conducted K-means cluster analysis based on the results of the hierarchical cluster analysis (i.e., the fivecluster solution). The number of cases in each cluster was as follows: cluster $1(\mathrm{~N}=53)$, cluster $2(\mathrm{~N}=83)$, cluster $3(\mathrm{~N}=29)$, cluster $4(\mathrm{~N}=103)$, and cluster $5(\mathrm{~N}=38)$. The final cluster centers of each cluster are summarized in Table 3. Cluster 1 has the highest means for the variables (i.e., the highest $\mathrm{SI}$ and $\mathrm{Cl}$ ), while cluster 3 has the lowest means for the variables (i.e., the lowest $\mathrm{SI}$ and $\mathrm{Cl}$ ). Cluster 2 has the second highest means for all variables (i.e., 2nd highest $\mathrm{SI}$ and $\mathrm{Cl}$ ). Clusters 4 and 5 varied: cluster 4 scored higher on subjective norms and personal image (i.e., moderate $\mathrm{SI}$ and low $\mathrm{Cl}$ ) than cluster 5 . However, relevance for learning and quality of learning results were lower than cluster 5 (i.e., low $\mathrm{SI}$ and moderate $\mathrm{Cl}$ ).

The results of the analysis of variance (ANOVA) indicated that there were significant differences among the groups in the variables: (1) subjective norms, $F(4,301)=186.228, p<.001$; (2) personal image, $F(4,301)=$ $117.804, p<.001 ;(3)$ relevance for learning, $F(4,301)=227.764, p<.001)$; and (4) quality of learning results, $F(4,301)=285.461, p<.001$. The results of Scheffe's post hoc multiple comparison test indicated that there were significant differences among the five clusters in subjective norms, personal image, relevance for learning, and quality of learning results. The final clusters are illustrated in Figure 2. 


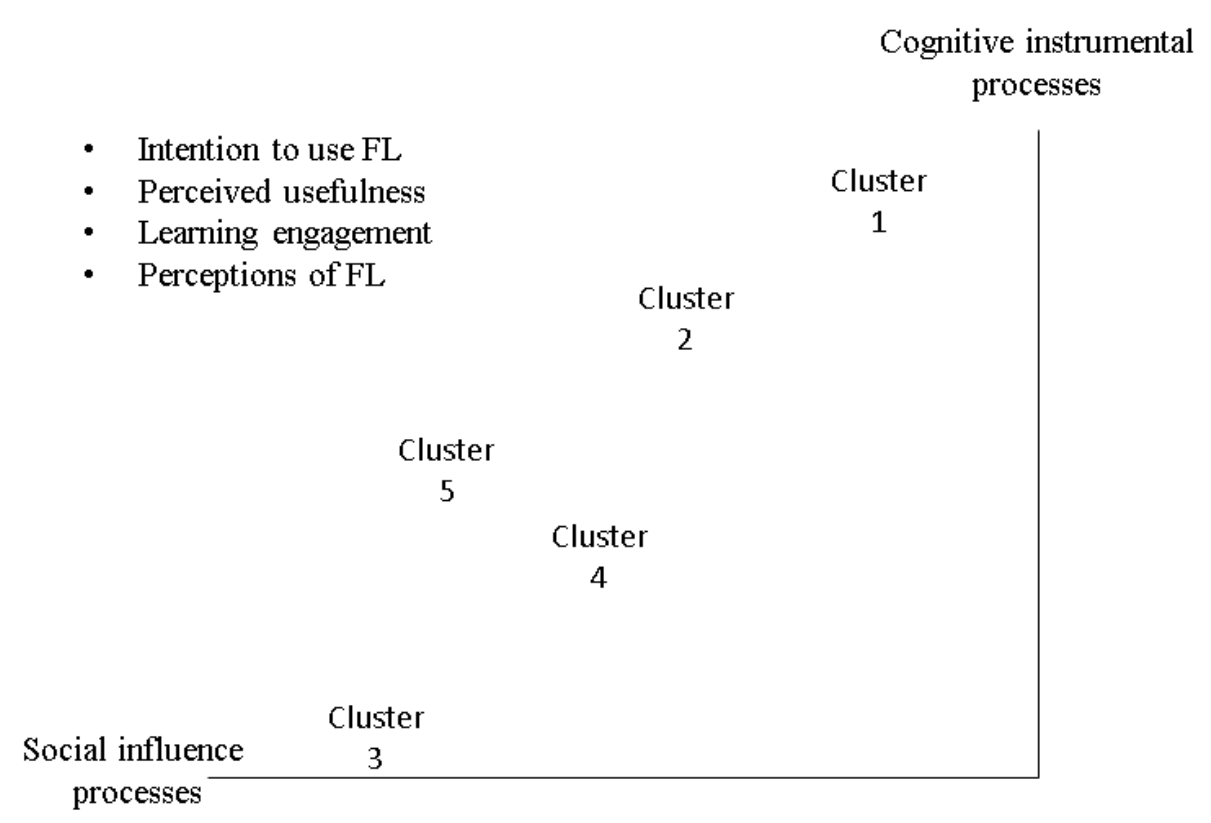

Figure 2. Five clusters using $\mathrm{SI}$ and $\mathrm{Cl}$ processes

Table 4. Comparisons between clusters

\begin{tabular}{lcccccc}
\hline & \multicolumn{7}{c}{ Clusters } & \multirow{2}{*}{ F-values } \\
\cline { 2 - 6 } & 1 & 2 & 3 & 4 & 5 & $124.85^{* *}$ \\
Perceived usefulness & $4.83(.36)$ & $4.46(.51)$ & $2.15(.83)$ & $3.64(.66)$ & $3.27(.69)$ & $77.53^{* *}$ \\
Registration intention & $4.89(.28)$ & $4.37(.76)$ & $2.12(1.06)$ & $3.57(.76)$ & $3.36(.99)$ & $73.43^{* *}$ \\
Learning engagement & $4.26(.78)$ & $3.66(.52)$ & $2.25(.70)$ & $3.12(.48)$ & $2.98(.48)$ & 78 \\
\hline
\end{tabular}

Note: ${ }^{* *} p<.001,{ }^{*} p<.05$

\begin{tabular}{lcccccccccc}
\hline & \multicolumn{7}{c}{ Scheffe post hoc multiple comparison test (p-values) } \\
\cline { 2 - 11 } & $1 \& 2$ & $1 \& 3$ & $1 \& 4$ & $1 \& 5$ & $2 \& 3$ & $2 \& 4$ & $2 \& 5$ & $3 \& 4$ & $3 \& 5$ & $4 \& 5$ \\
\hline Perceived usefulness & .016 & .000 & .000 & .000 & .000 & .000 & .000 & .000 & .000 & .037 \\
Registration intention & .005 & .000 & .000 & .000 & .000 & .000 & .000 & .000 & .000 & .715 \\
Learning engagement & .000 & .000 & .000 & .000 & .000 & .000 & .000 & .000 & .000 & .788 \\
\hline
\end{tabular}

\section{Differences in Perceived Usefulness, Intention to Use, and Learning Engagement in Flipped Learning}

We compared the five clusters in intention to register for flipped learning classes, perceived usefulness, and learning engagement in flipped learning using an analysis of variance (ANOVA). Cluster 1 had the highest scores on perceived usefulness, intention to register for flipped learning classes, and learning engagement whereas cluster 3 had the lowest scores on the three variables. Cluster 4 (moderate $\mathrm{SI}$ and low $\mathrm{Cl}$ ) had higher scores on the three variables than cluster 5 (low SI and moderate $\mathrm{Cl}$ ); however, there was statistical significance only between clusters 4 and 5 on perceived usefulness. Table 4 shows the results of the analysis of variance (ANOVA), indicating that there were significant differences among the five clusters in perceived usefulness $(F(4,301)=124.85, p<.001)$, intention to register for flipped classes $(F(4,301)=77.53, p<.001)$, and learning engagement $(F(4,301)=73.43, p<.001)$. Scheffe's post hoc test showed that there were also significant differences among clusters in perceived usefulness at the $p<.05$ level; however, no significant differences were found between clusters 4 and 5 in intention to register for flipped learning classes and learning engagement. 
Table 5. Preference for flipped learning

\begin{tabular}{lccccc}
\hline Cluster centers & Cluster 1 & Cluster 2 & Cluster 3 & Cluster 4 & Cluster 5 \\
\hline Positive & $92.5 \%$ & $100.0 \%$ & $27.6 \%$ & $74.8 \%$ & $84.2 \%$ \\
Negative & $3.8 \%$ & - & $58 . \%$ & $12.6 \%$ & $13.2 \%$ \\
Neutral or no answer & $3.8 \%$ & - & $13.8 \%$ & $12.6 \%$ & $2.6 \%$ \\
\hline
\end{tabular}

Table 6. Perceptions of flipped learning

\begin{tabular}{|c|c|c|c|c|c|c|c|}
\hline \multirow[b]{2}{*}{ Category } & \multirow[b]{2}{*}{ Sub-categories } & \multicolumn{5}{|c|}{ Cluster } & \multirow[b]{2}{*}{ Total } \\
\hline & & $\begin{array}{c}1 \\
(N=53)\end{array}$ & $\begin{array}{c}2 \\
(N=83)\end{array}$ & $\begin{array}{c}3 \\
(N=29)\end{array}$ & $\begin{array}{c}4 \\
(N=103)\end{array}$ & $\begin{array}{c}5 \\
(N=38)\end{array}$ & \\
\hline \multirow{5}{*}{$\begin{array}{l}\text { Pre-learning } \\
\text { opportunities }\end{array}$} & Online pre-learning materials & 20 & 35 & 1 & 37 & 14 & 107 \\
\hline & Review opportunity for learning & 7 & 7 & 0 & 10 & 4 & 28 \\
\hline & Individualized learning & 3 & 3 & 0 & 6 & 2 & 14 \\
\hline & Self-directed learning & 2 & 6 & 0 & 2 & 1 & 11 \\
\hline & Flexibility in learning time & 3 & 7 & 0 & 5 & 2 & 17 \\
\hline \multirow{3}{*}{ Class activities } & Question opportunities in class & 2 & 0 & 0 & 1 & 0 & 3 \\
\hline & In-class discussion & 2 & 6 & 0 & 6 & 3 & 17 \\
\hline & $\begin{array}{l}\text { Active participation in class activities (other } \\
\text { than discussion or questions) }\end{array}$ & 1 & 4 & 1 & 2 & 1 & 9 \\
\hline \multirow{7}{*}{$\begin{array}{l}\text { Learning } \\
\text { outcomes }\end{array}$} & Understanding of lectures & 7 & 14 & 1 & 9 & 2 & 33 \\
\hline & Retention of learning & 2 & 2 & 1 & 0 & 0 & 5 \\
\hline & Critical thinking & 0 & 0 & 0 & 0 & 1 & 1 \\
\hline & Efficiency of learning & 0 & 0 & 0 & 2 & 4 & 6 \\
\hline & No learning effectiveness & 0 & 0 & 15 & 12 & 2 & 29 \\
\hline & Learning motivation & 0 & 0 & 0 & 3 & 0 & 3 \\
\hline & Learning engagement and fun & 0 & 4 & 0 & 1 & 2 & 7 \\
\hline \multirow{2}{*}{ Others } & Amount of learning & 2 & 3 & 1 & 2 & 1 & 9 \\
\hline & Excessive time for learning & 0 & 0 & 4 & 1 & 0 & 5 \\
\hline Total & & 51 & 91 & 24 & 99 & 39 & 304 \\
\hline
\end{tabular}

\section{Students' Perceptions of Flipped Learning}

Students' perceptions of flipped learning as reported in open-ended responses were analyzed using NVivo 12 , qualitative data analyses software. Among the 304 comments about the perceptions of flipped learning, $78.6 \%$ were positive and $12.1 \%$ were negative (9.3\% were neutral or missing values). Each cluster revealed different perceptions of flipped learning and there were significant differences among the five clusters $\left(\chi^{2}(4)\right.$ $=80.321, \mathrm{p}<.001)$, as shown in Table 5 .

\section{The Signature of Flipped Learning: Online Pre-Learning Sessions}

The author performed pilot coding of verbatim responses and generated four categories (i.e., pre-learning materials, class activities, learning outcomes, and others) and 17 sub-categories (see Table 6). Since coding was completed by a single researcher, the coding was done twice with a time lapse interval of one week to ensure reliability. This iterative process enabled the researchers to develop mutually exclusive and conceptually congruent codes (Merriam, 1998). Misplaced and double-meaning codes were revised through this iterative process. The cluster comparisons of the perceptions of flipped learning are illustrated in Table 6.

The most frequent comments about the perceptions of flipped learning were "using pre-learning online materials" ( $N=107,35.2 \%)$. Sample verbatim statements include, "Online pre-learning materials help me understand the class more effectively" (Cluster 1, female/junior/Energy engineering), and "It is good to know in advance what I will learn in class due to online pre-learning materials" (Cluster 2, female/sophomore/Fashion design). Review opportunities for learning were also mentioned as the strength of flipped learning, such as "Flipped learning allows me to repeat the pre-learning materials until I 
understand" (Cluster 1, female/junior/Education), and "It gives me learning opportunities to understand what I missed in class" (Cluster 4, male/senior/Nano science). A freshman student elaborated further on her response:

Once I miss a lecture in class, there is no way to do damage control and it negatively affects the remaining classes. Or sometimes, I cannot concentrate on lectures because of my physical condition. However, flipped learning allows me to study wherever I am, such as at home or even on the subway and to re-play and repeat as many times as I want. That's why I think that flipped learning is a more effective instructional approach than lectures.

(Cluster 1/female/freshman/Education).

\title{
Effectiveness and efficiency of flipped learning: Learning outcomes and class activities
}

There were also comments about the strengths of flipped learning including individualization and selfdirected learning. Sample statements include, "I can selectively focus on what I deem to be important and skip the remaining parts" (Cluster 4, female/freshman/Education), "The strength of flipped learning is that I can repeatedly play pre-learning materials at my own pace. I like listening to the online lectures over and over again at a faster speed and flipped learning fits my needs. Since the online materials remain on Blackboard, I can look up the part I don't understand in the lecture after class" (Cluster 1, female/freshmen/Chemistry) [Individualization], and "Flipped learning is an appropriate instructional approach to facilitate students' own understanding of learning materials and problem-solving skills" (Cluster 2, male/freshman/Chemistry) [Self-directed learning].

As for class activities, three sub-categories emerged: (1) question opportunities, (2) in-depth discussion, and (3) active participation in other class activities. In-depth discussion was mentioned the most ( $N=17)$ : "In flipped learning, I can discuss about an issue with others who have different perspectives" (Cluster 2, male/junior/Hospitality), and "Flipped learning is effective because I can share what I learned from prelearning online materials with classmates in the discussion" (Cluster 4, female/sophomore/Education).

Many participants reported on the learning effectiveness of flipped learning $(\mathrm{N}=55)$, such as facilitating "understanding of lectures" ( $N=33$ ), "efficiency of learning" ( $N=6)$, and "retention of learning" $(N=5)$. Sample statements include:

\begin{abstract}
Sometimes cognitive overload occurs in class because students are required to immediately understand what they just (or concurrently) learned. Flipped learning allows students to understand the learning content at their own pace. It also includes many class activities, not just lecturing, so it helps understanding of learning (Cluster 4, female/senior/Economics).
\end{abstract}

Another statement is "Since online pre-learning materials facilitate understanding of lectures, it helps retention of learning without additional efforts for learning" (Cluster2, male/senior/Physical education).

Comments about learning motivation ( $N=3$ ), fun, and learning engagement $(\mathrm{N}=7)$, include, "In flipped learning, I have clear learning motivation to participate in class activities" (Cluster 4, male/sophomore/Energy engineering), "[Flipped learning is] less boring than lectures" (Cluster 5, male/senior/Nano science), and "The retention of learning improved in flipped learning because it is fun" (Cluster 5, female/sophomore/Media communication).

\section{Negative perspectives on flipped learning}

There were also negative comments about the effectiveness of flipped learning ( $N=29)$. Most of the negative comments were from students in clusters 3 and 4 . Sample statements include: 
Flipped learning is not effective for me. The online video materials are too lengthy. I don't see a connection between the video materials and lectures. I prefer succinct lectures in class. Many students play the online video materials at $2 x$ speed or listen to them at one sitting, so it does not help (Cluster 3, female/sophomore/Music).

and "I don't see the big difference [between flipped learning and traditional lectures]" (Cluster 4, female/senior/Animation). There were also complaints about the required learning time for flipped learning online materials, such as "Flipped learning requires excessive preparation time besides class hours" (Cluster 3, male/junior/English).

\section{DISCUSSION}

This study investigated flipped learners' perceptions, perceived use, intention to register for flipped learning classes, and learning engagement using cluster analysis. We classified 306 flipped learners into five clusters based on their level of social influence $(\mathrm{SI})$ and cognitive instrumental $(\mathrm{Cl})$ processes using TAM2 (Venkatesh \& Davis, 2000). The results of cluster analysis yielded the following combinations: cluster $1(N=53$, highest $\mathrm{SI}$ and $\mathrm{Cl})$, cluster $2(\mathrm{~N}=83$, the second highest $\mathrm{SI}$ and $\mathrm{Cl})$, cluster $3(\mathrm{~N}=29$, lowest $\mathrm{SI}$ and $\mathrm{Cl})$, cluster $4(\mathrm{~N}=103$, moderate $\mathrm{SI}$ and low $\mathrm{Cl})$, and cluster $5(\mathrm{~N}=38$, low $\mathrm{SI}$ and moderate $\mathrm{Cl})$. There were statistically significant differences among the five clusters in perceived usefulness, intention to register for flipped learning classes, and learning engagement. These differences confirmed the validity of the cluster classification using social influence and cognitive instrumental processes. The results of a post hoc test indicated that those who had moderate the social influence process with a low cognitive instrumental process (cluster 4 ) had statistically higher perceived usefulness for flipped learning than students who had low social influence with a moderate cognitive instrumental process (cluster 5). That is, those who perceived that their professors, parents, or friends had high expectations of them (subjective norm) and those who wanted to portray a good image in class or at school (personal image) were likely to have a higher level of perceived usefulness of flipped learning than students who understood the relevance of flipped learning and expected successful learning outcomes in flipped learning classes. However, there were no significant differences between clusters 4 and 5 in intention to register for flipped learning classes and learning engagement in flipped learning. For practical implications, instructors and school administrators should consider the social influence process and cognitive instrumental process together to predict students' intention to register for flipped classes and learning engagement.

In this study, $78.6 \%$ of the participants had a positive perception of flipped learning. This is higher than Hao's (2016) survey results (roughly 60\%). Of the 306 participants, 196 participants (64.1\%) stated that they intended to take flipped learning classes in the future, which is also higher than Hao's study (44\%), and Forsey et al.'s (2013) study (53\%). The discrepancies between students' general perception and the intention to take flipped learning classes indicate that there are still areas for improvement in flipped learning classes. It is necessary to investigate why those who were positive about flipped learning were also reluctant to take flipped learning classes in the future.

Students' perceptions of and preferences for flipped learning were statistically different among the five clusters. Most participants in clusters 1 (highest $\mathrm{SI}$ and $\mathrm{Cl}$ ) and 2 (second highest $\mathrm{SI}$ and $\mathrm{Cl}$ ) were positive about flipped learning as an instructional approach ( $92.5 \%$ and $100 \%$ respectively). However, $58 \%$ of cluster 3 (lowest $\mathrm{SI}$ and $\mathrm{Cl}$ ) were negative about flipped learning and only $27.6 \%$ were positive. This finding indicates that the social influence process and the cognitive instrumental process of TAM are valid predictors of students' perceptions of flipped learning. Cluster 5 (low SI and moderate $\mathrm{Cl}$ ) was more positive about flipped learning (84.2\%) than cluster 4 (moderate $\mathrm{SI}$ and low $\mathrm{Cl}$ ) (74.8\%). However, there were no significant differences in the negative perceptions of flipped learning between clusters $4(12.6 \%)$ and $5(13.2 \%)$. This result indicates that there is a wide range of student perceptions of flipped learning, and it is necessary to provide customized learning support and implement instructional strategies for each type of flipped learners. Given that there were no significant differences in students' perceptions and preferences between the cluster with a high social influence process and low cognitive instrumental process and the cluster with 
reversed features (i.e., vice versa), the social influence process and cognitive instrumental process must be considered together instead of separately for use in cluster analysis.

We analyzed the participants' open-ended comments about their perceptions of flipped learning, such as why they liked or disliked flipped learning $(\mathrm{N}=304)$. The following four themes emerged: (1) online prelearning opportunities, (2) class activities, (3) learning outcomes, (4) other (e.g., workload and learning times). The most frequent comments about flipped learnng was online pre-learning sessions. This result confirmed previous research findings that have emphasized the importance of pre-learning sessions in flipped learning by Lee and Choi (2019), Lo and Hew (2017), and Steen-Utheim and Foldnes (2018). An online pre-learning session must appear to be a distinctive feature to students. Students recognized that these sessions are useful for their learning because it makes it possible to "facilitate understanding of lectures," "review opportunities for learning," "[provide] flexible learning time," "individualized learning," and "meaningful in-class discussions." As Lee and Choi (2019), and Lo and Hew (2017) emphasized, providing students with high-quality pre-session learning materials is critical to the success of flipped learning. Considering the importance of pre-learning sessions in a flipped learning class, instructors should encourage students to complete the pre-learning sessions and school administrators should provide those who teach flipped classes with sufficient support to produce high quality pre-learning materials.

It is noticeable that affective domains, such as learning motivation, learning engagement, and fun, were included in the perceptions of flipped learning as a strength of flipped learning. These advantages are similar to the research findings by Steen-Utheim and Foldnes (2018), Hao (2016), Nouri (2016), and Forsey et al. (2013). Hao's (2016) research included "recognition of learning needs," "more interaction in classes," and "more effective use of class time," and Nouri's (2016) conclusions, included "flexibility and mobility of learning," "support for learning," and "meaningful learning activities." Our research findings also substantially overlap with Forsey et al.'s (2013) observations, including "flexibility," "richness of learning contents," and "productivity in learning," and Wang and Zhu's (2019) findings about flipped class students' preferences for student-student interaction and active learning results in class. This finding indicates that students recognize flipped learning as an instructional approach that they can have fun with and that it can enhance learning motivation and learning engagement. Steen-Utheim and Foldnes (2018) emphasized the affective aspects of learning engagement in flipped learning, stating that it is necessary to make flipped learning experiences more meaningful by making efforts to increase learning motivation, learning engagement, and even fun.

The students also had negative perceptions of flipped learning, including "no learning effectiveness" and "excessive time for learning." This finding supported the research results by He et al. (2016), Forsey et al. (2013), and Hao (2016). Even though students' perceptions of flipped learning were largely positive, He et al. (2016) explained that there is a wide spectrum of students' perception of flipped learning varies from positive to negative. Forsey et al. (2013) indicated that students were anxious about replacing instructor-led class lectures with online pre-learning materials. Finally, Hao (2016) found that slight less than $40 \%$ of flipped learners reported that flipped learning satisfied with their learning needs, indicating that students disliked the "requirement self-discipline," "requirement of prior knowledge and academic motivation," and "less learner control" in flipped learning.

In this study, we found that participants' perceptions of flipped learning are different by cluster. There was no single negative comment from cluster 1 (highest $\mathrm{SI}$ and $\mathrm{Cl}$ ) or cluster 2 (second highest $\mathrm{SI}$ and $\mathrm{Cl}$ ). Negative comments, such as "no learning effectiveness" and "excessive time for learning" mostly came from students in cluster 3 (lowest $\mathrm{SI}$ and $\mathrm{Cl}$ ). Interestingly, there were more negative comments from students in cluster 4 (moderate $\mathrm{SI}$ and low $\mathrm{Cl}$ ) than cluster 5 (low SI and moderate $\mathrm{Cl}$ ). These findings confirm Nouri's (2006) research that different flipped learner groups have different perceptions of flipped learning.

There are two plausible explanations about the discrepancies between the previous literature and the current study. First, most negative comments came from the group with low social influence and cognitive instrumental process and their perceived usefulness, intention to register for flipped learning classes, and learning engagement were the lowest of all the clusters. Hence, this finding should be interpreted considering 
the research design (i.e., cluster analysis). The other reason may be that these perceptions may also be influenced by how instructors implement flipped learning, such as the flipped class policies or grading system. For example, Wang and Zhu (2019) explained that the quality of pre-learning materials is an influencing factor of students' satisfaction level of MOOCs.

Therefore, it is necessary to identify meaningful variables to segment flipped learners so instructors can implement effective, practical, and feasible instructional strategies and provide appropriate learning support to attain learning outcomes.

\section{Limitations and Recommendations for Future Research}

This study has several limitations. It is important to point out these limitations for those who are interested in extending the current study. We used cluster analysis as an analytic method in this study. The results of cluster analysis may change depending on which variables are used to classify the clusters (e.g., $\mathrm{SI}$ and $\mathrm{Cl}$ processes in the current study, learning achievement, or social economic status). If future researchers select different variables to classify respondents using cluster analysis, the results may be different. Therefore, it is important to choose reasonable and meaningful variables to select and classify respondents considering the research purpose. Cluster analysis is a practical method to classify a large number of respondents with homogenous characteristics into meaningful clusters. However, Pastor (2010) explained that cluster analysis could yield clusters by creating a structure even if the structure does not actually exist (e.g., exploratory factor analysis). While the validity of the results of exploratory factor analysis can be examined using confirmatory factor analysis, cluster analysis does not have a specific analytic technique to validate the results. Thus, it can be validated using an analysis of variance (ANOVA) or chi square tests with different variables.

Another limitation of this study is the limited generalizability since this study was conducted with undergraduate students who were enrolled in flipped learning classes in Korea. Future studies are encouraged to expand the scope with participants from different countries or in multicultural contexts. In addition, we included an open-ended question in the survey to investigate the participants' perceptions of flipped learning. Future researchers who extend the current research should collect more qualitative data, such as focus group interviews or individual in-depth interviews to obtain robust, rich, and vivid research findings. He et al. (2016) criticized many flipped learning studies that were conducted without proper controls to validate the effects of treatment. This study also did not have a comparison group (e.g., those who were enrolled in the same courses delivered in traditional classroom) for a practical reason. Future studies should use a solid research method and control extraneous variables to validate the research findings in this study. Finally, given that the current study is limited to examining the differences among the clusters in perceived usefulness, learning engagement, perceptions of flipped learning, and intention to register for flipped learning classes, future studies are strongly encouraged to expand the scope of this study by examining group differences in academic achievement or learning outcomes.

\section{CONCLUSIONS}

Flipped learning is a popular instructional approach in higher education. A frequently emphasized strength of flipped learning is the cost-effectiveness and efficiency to implement a learner-cantered approach to a large number of students. However, students have unique learner characteristics and needs. We cannot ignore these individual differences for educational purposes, but we also cannot completely customize programs for every single student. It is necessary to compromise between the ideal and the possible. If we identify critical factors to classify meaningful learner groups in flipped learning, it may enable us to provide students with significant and feasible customized learning support. The phrase "one size does not fit all" applies to flipped learning.

Funding: This study was supported by 2020 Research Grant from Kangwon National University.

Declaration of interest: Author declares no competing interest.

Data availability: Data generated or analysed during this study are available from the author on request. 


\section{REFERENCES}

Abdullah, F., \& Ward, R. (2016). Developing a general extended technology acceptance model for ELearning (GETAMEL) by analyzing commonly used external factors. Computers in Human Behavior, 56, 238-256. https://doi.org/10.1016/j.chb.2015.11.036

Agudo-Peregrina, A. F., Hernandez-Garcia, A., \& Pascual-Miguel, F. J. (2014). Behavioral intention, use behavior, and the acceptance of electronic learning systems: Differences between higher education and lifelong learning. Computers in Human Behavior, 34, 301-314. https://doi.org/10.1016/j.chb.2013.10.035

Aldenderfer, M. S., \& Balshfield, R. K. (1984). Cluster analysis. Sage publication. https://doi.org/10.4135/9781412983648

Al-Samarraie, H., Shamsuddin, A., \& Alzahrani, A. I. (2020). A flipped classroom model in higher education: a review of the evidence across disciplines. Educational Technology Research Development, 68(3), 10171051. https://doi.org/10.1007/s11423-019-09718-8

Bergmann, J., \& Sams, A. (2012). Flip your classroom: Reach every student in every class every day. International Society for Technology in Education.

Chen Hsieh, J. S., Huang, Y. M., \& Wu, W. C. V. (2017). Technological acceptance of LINE in flipped EFL oral training. Computers in Human Behavior, 70, 178-190. https://doi.org/10.1016/j.chb.2016.12.066

Davis, F. (1989). Perceived usefulness, perceived ease of use, and user acceptance of information technology. MIS Quarterly, 13(3), 319-340. https://doi.org/10.2307/249008

Flip Learning (2014). Definition of flipped learning. Flip Learning Organization. https://flippedlearning.org/definition-of-flipped-learning

Forsey, M., Low, M., \& Glance, D. (2013). Flipping the sociology classroom: Towards a practice of online pedagogy. The Australian Sociological Association, 49(4), 471-485. https://doi.org/10.1177/1440783313504059

Fulton, K. (2012). Upside down and inside out: Flip your classroom to improve student learning. Learning \& Leading with Technology, 39(8), 12-17.

George, D., \& Mallery, P. (2010). SPSS for windows step by step: A simple guide and reference. Pearson Education.

Goodwin, B., \& Miller, K. (2013). Research says /evidence on flipped classrooms is still coming in. TechnologyRich Learning, 70(6), 78-80.

Hao, Y. (2016). Exploring undergraduates' perspectives and flipped learning readiness in their flipped classrooms. Computers in Human Behavior, 59, 82-92. https://doi.org/10.1016/j.chb.2016.01.032

He, W., Holton, A., Farkas, G., \& Warschauer, M. (2016). The effects of flipped instruction on out-of-class study time, exam performance, and student perceptions. Learning \& Instruction, 45, 61-71. https://doi.org/10.1016/j.learninstruc.2016.07.001

Hwang, G., Yin, C., \& Chu, H. (2019). The era of flipped learning: promoting active learning and higher order thinking with innovative flipped learning strategies and supporting systems. Interactive Learning Environments, 27(8), 991-994. https://doi.org/10.1080/10494820.2019.1667150

Johnson, L., Adams Becker, S., Estrada, V., \& Freeman, A. (2015). NMC Horizon report: 2015 higher education edition. The New Media Consortium. 
Koh, J. H. L. (2019). Four pedagogical dimensions for understanding flipped classroom practices in higher education: A systematic review. Educational Sciences: Theory \& Practice, 19(4), 14-33. https://doi.org/10.12738/estp.2019.4.002

Lee, J. \& Choi, H. (2019). Rethinking the flipped learning pre-class: Its influence on the success of flipped learning and related factors. British Journal of Educational Technology, 50(2), 934-945. https://doi.org/10.1111/bjet.12618

McDonald, K., \& Smith, C. M. (2013). The flipped classroom for professional development: Part I. Benefits and strategies. The Journal of Continuing Education in Nursing, 44(10), 437-438. https://doi.org/10.3928/00220124-20130925-19

Merriam, S. B. (1998). Qualitative research and case study applications in education. Jossey-Bass Publishers.

Mitchell, T. R., \& Beach, L. R. (1976). A review of occupational preference and choice research using expectancy theory and decision theory. Journal of Occupational Psychology, 49, 231-248. https://doi.org/10.1111/j.2044-8325.1976.tb00348.x

$\mathrm{Ng}, \mathrm{E} . \mathrm{M} . \mathrm{W}$. (2018). Integrating self-regulation principles with flipped classroom pedagogy for first year university students. Computers \& Education, 126, 65-74. https://doi.org/10.1016/j.compedu.2018.07.002

Nouri, J. (2016). The flipped classroom: for active, effective and increased learning - especially for low achievers. International Journal Educational Technology in Higher Education, 13, 33. https://doi.org/10.1186/s41239-016-0032-z

O'Flaherty, J., \& Phillips, C. (2015). The use of flipped classrooms in higher education: A scoping review. The Internet and Higher Education, 25, 85-95. https://doi.org/10.1016/j.iheduc.2015.02.002

Park, S. Y., Nam, M.W. \& Cha. S. B. (2012). University students' behavioral intention to use mobile learning: Evaluating the technology acceptance model. British Journal of Educational Technology, 43(4), 592605. https://doi.org/10.1111/j.1467-8535.2011.01229.x

Pastor, D. A. (2010). Cluster analysis. In G. R. Hancock, \& R. O. Muller (Eds.), The reviewer's guide to quantitative methods in the social sciences (pp. 41-54). Routledge.

Podsakoff, P., MacKenzie, S., Lee, J., \& Podsakoff, N. (2003). Common method biases in behavioral research: A critical review of the literature and recommended remedies. Journal of Applied Psychology, 88(5), 879-903. https://doi.org/10.1037/0021-9010.88.5.879

Schreiner, L. A., \& Louis, M. C. (2011). The engaged learning index: Implications for faculty development. Journal on Excellence in College Teaching, 22(1), 5-28.

Steen-Utheim, A. T. \& Foldnes, N. (2018). A qualitative investigation of student engagement in a flipped classroom. Teaching in Higher Education, 23(3), 307-324. https://doi.org/10.1080/13562517.2017.1379481

Venkatesh, V., \& Davis, F. D. (2000). A theoretical extension of the technology acceptance model: Four longitudinal field studies. Management Science, 46(2), 186-204. https://doi.org/10.1287/mnsc.46.2.186.11926

Wang, K., \& Zhu, C. (2019). MOOC-based flipped learning in higher education: Students' participation, experience and learning performance. International Journal Educational Technology in Higher Education, 16, 33. https://doi.org/10.1186/s41239-019-0163-0

Correspondence: Min Young Doo, Department of Education, College of Education, Kangwon National University, South Korea. E-mail: mydoo@Kangwon.ac.kr 